\title{
DANÇA E EXPERIÊNCIA ESTÉTICA: A EXTENSÃO UNIVERSITÁRIA EM CENA
}

\section{DANCE AND AESTHETIC EXPERIENCE: THE UNIVERSITY EXTENSION SCENE}

\author{
Deizi Domingues da Rocha ${ }^{1}$ e Neusa Dendena Kleinubing ${ }^{2}$
}

\begin{abstract}
RESUMO
Este texto apresenta resultados de intervenções a partir do projeto de extensão Contradança da Universidade Comunitária da Região de Chapecó - Unochapecó/SC, que teve como objetivo, em 2011, promover junto aos professores do ensino especializado e da rede pública estadual de ensino, espaços de vivências e discussões sobre a dança, refletindo sua contribuindo no processo de formação humana e de (re)conhecimento da diversidade. O estudo se desenvolveu a partir dos pressupostos da pesquisa-ação (THIOLLENT, 2007). As ações ocorreram no período de maio a outubro de 2011, envolvendo cinco instituições, sendo três no âmbito do ensino especializado para o trabalho com pessoas com deficiência e duas escolas da rede estadual de ensino. A análise ora apresentada decorre da análise do questionário com perguntas abertas, respondidas pelas professoras participantes das oficinas de dança. Os dados sinalizam que as oficinas contribuíram para a construção de um novo olhar para o corpo diferente e para a dança que esses corpos realizam e que esta prática pode ser compreendida como capaz de nos sensibilizar para a beleza de todos os corpos, nas suas singularidades e potencialidades.
\end{abstract}

Palavras-chave: Extensão universitária. Experiência Estética. Dança. Diversidade.

\begin{abstract}
This paper presents results of interventions from the extension project Contradança of the UniversidadeComunitária da Região de Chapecó-Unochapecó/SC, which aimed, in 2011, to promote with teachers of special education and state public education, spaces of experiences and discussions about the dance, reflecting its contributing in the process of human formation and knowledge of the diversity. The study was developed from the assumptions of action research (Thiollent, 2007). The actions occurred in the period from May to October 2011, involving five institutions, three in teaching specialized in working with people with disabilities and two public schools. The analysis presented here follows the analysis of the questionnaire with open questions answered by the teachers participating in the dance workshops. The data indicate that the workshops contributed to the construction of a new look at the different body and the dance that carry these bodies and that this practice can be understood as able to sensitize us to the beauty of all bodies, in their uniqueness and potential.
\end{abstract}

Keywords: University extension. Aesthetic experience. Dance. Diversity.

\footnotetext{
${ }^{1}$ Universidade Comunitária da Região de Chapecó - Unochapecó. Email: deizirocha@unochapeco.edu.br

${ }^{2}$ Universidade Comunitária da Região de Chapecó - Unochapecó. Email: neusadk@gmail.com
} 


\section{INTRODUÇÃO}

Nos últimos anos, temos acompanhado diferentes discussões em torno do papel da extensão universitária no processo de formação acadêmica e como prática que aproxima sociedade e universidade. Melo Neto (2003, p. 15) aponta que o trabalho da extensão "se volta à produção do conhecimento novo, dando um papel também social a esse produto da atividade extensionista".

Nesse sentido, a extensão universitária não é vista como prática esporádica na qual o conhecimento produzido na academia é repassado à comunidade, mas sim como um processo no qual universidade e comunidade "conversam", como um processo fundamentado na relação teoria-prática, e na possibilidade de troca de saberes entre os atores acadêmicos - professores e estudantes - e os atores que compõem o público alvo da ação extensionista, sinalizando as demandas existentes na sociedade.

Nesse processo, o curso de Educação Física da Universidade Comunitária da Região de Chapecó - Unochapecó desenvolve um número expressivo de ações em diversos contextos, tendo as práticas corporais da cultura de movimento como conteúdos trabalhados com diferentes populações, a exemplo do projeto de extensão denominado "Contradança", objeto de reflexão deste texto. Alicerçado pelos princípios da educação estética,este projeto preconiza a dança como possibilidade de todos os corpos visando através dessa arte, contribuir para o processo de emancipação dos sujeitos. Iniciando suas ações em 2009, quando o objetivo foi divulgar uma proposta de dança que "foge aos padrões" e contribuir para a formação de novo olhar para as pessoas com deficiência. O projeto teve grande repercussão nas instituições de ensino especializado e nas escolas da rede regular que assistiram à mostra de dança, no município de Chapecó - SC. A partir disso, em 2010 o projeto propôs oficinas de dança nas quais crianças, adolescentes e adultos com deficiência dançaram conjuntamente com escolares e professores da rede regular de ensino. Este foi um momento ímpar que possibilitou visualizar a necessidade de ações do projeto Contradança também nesse contexto.

Assim, fortalecidos pelas experiências anteriores ousamos em 2011, propor atividades que envolvessem diretamente os professores, tanto do ensino especializado quanto do ensino regular. Entendemos que em tempos de escola inclusiva, oferecer subsídios para que os professores vivenciem e reflitam sobre o "corpo diferente" que chega à escola é de fundamental importância, afinal são eles os mediadores entre o sujeito e o conhecimento a ser 
adquirido, produzido. Assim, tentar compreender melhor que corpo é este, como é possível a ele sentir, perceber e aprender é condição primeira para que o processo de formação aconteça. Nesse sentido, o foco das ações deste projeto em 2011, foi promover junto aos professores do ensino especializado e da rede pública estadual de ensino, espaços de vivências e discussões através da dança, refletindo sobre a dança e sua relação no processo de formação humana e de (re)conhecimento da diversidade. Para isso foram realizados encontros em formato de oficinas de dança nas quais os professores puderam experimentá-la como possibilidade estéticoexpressiva.

Na sequência apresentamos o caminho metodológico traçado nesta ação e os resultados obtidos com relação às percepções dos professores referente aos encontros nos quais a dança foi desenvolvida, bem como as implicações no modo de pensar o movimento, o corpo e a dança a partir das vivências práticas.

\section{Do caminho metodológico}

As reflexões realizadas neste estudo são oriundas de um projeto de extensão universitária que se pauta nos princípios da pesquisa-ação para suas intervenções pedagógicas nos diferentes espaços. Sendo as atividades do projeto de essência prática, seguimos as orientações de Thiollent (2007) quando diz que este modo de fazer e pensar as intervenções deve estar de acordo com as exigências próprias da ação e participação dos sujeitos envolvidos na situação pesquisada. As ações do projeto Contradança aqui apresentadas, ocorreram no período de maio a outubro de 2011, envolvendo cinco instituições, sendo três no âmbito do ensino especializado para o trabalho com pessoas com deficiência: 1) Escola Recanto da Esperança - APAE Chapecó; 2) Associação de deficientes visuais do oeste de Santa Catarina - ADEVOSC; e 3) Centro Associativo de Atividades Psicofísicas Patrick CAPP ) e duas escolas regulares da rede estadual de ensino: 1) Escola Educação Básica Coronel Lara Ribas e 2) Escola de Educação Básica Professora Luiza Santin. As duas escolas foram escolhidas por apresentarem um grande número de crianças e adolescentes com deficiência incluídos no sistema de ensino.

As ações aconteceram em quatro momentos distintos e cerca de 130 professores participaram das atividades. Neste texto discutiremos os dados coletados ao final do terceiro momento/encontro, quando os participantes foram convidados a responder um questionário que continha questões relacionados às atividades até então vivenciadas. 
Na sequência apresentamos, brevemente, a forma como cada encontro foi organizado e a metodologia utilizada:

1. "Encontro, denominado de "Contradança: a dança de todos os corpos", teve como objetivo o diagnóstico situacional e iniciar o processo de sensibilização para a dança. Esse momento fomentou o imaginário criativo, a sensibilidade do "ser" para as coisas, sentidos, emoções, percepções que movem a criatividade, bem como estimulou a capacidade de criação em dança. Para isso propomos laboratórios explorando a percepção e atenção corporal a partir da inspiração e expiração, (re)descobrindo as articulações e suas possibilidades de movimentos para ampliar a percepção com relação ao próprio corpo. Na sequência, o trabalho em duplas e em pequenos grupos deu suporte para discutirmos a necessidade e a importância do corpo-outro na constituição da nossa subjetividade ou, dito de outra forma, na constituição daquilo que somos.

2. Encontro, intitulado "Contradança: caminhos da sensibilização", teve como foco o exercício da alteridade, ou como os professores concluíram ao final deste momento, a necessidade do exercício de nos colocarmos no lugar do outro. Iniciamos as atividades impondo a condição de que todos deveriam criar uma situação de restrição ou de limitação corporal. Além do processo de alteridade, isto é, de vivenciar e pensar "meu ser/estar corpo" e o "meu ser/estar corpo no lugar do outro", os objetivos pautaram-se em proporcionar ao corpo em movimento possibilidades de realização, descoberta, criação de movimentos que se relacionam de forma qualitativa com o tempo, espaço e fluência. Dessa instrumentalização e,pela bagagem de experiência corporal, a ideia foi explorar diferentes formas de movimento em diferentes espaços, bem como com pessoas diferentes já que trabalhamos de forma individual,em dupla, trio e coletivamente. É importante ressaltar que neste encontro as três instituições de ensino especializado, reuniram-se num único espaço,o que proporcionou integração entre estas instituições.

3. ${ }^{\circ}$ Encontro, denominado de "Contradança: dançando com a diversidade", teve como proposta a composição em dança a partir das células coreográficas que surgiram nos encontros anteriores. Utilizando-se das suas experiências e vivências de movimento para a dança os professores deram forma às ideias. A partir da temática surgida em cada instituição, os participantes criaram um roteiro para orientar a construção das coreografias. Nesse momento organizaram os aspectos coreológicos da dança, tais como os níveis, os fatores, trajetória, bem como introduziram possíveis efeitos coreográficos (saídas de palco, tempo, elementos cênicos, paragens, reorganização de células de movimento, repetição, voz, 
interação com o público, entre outras), e trabalharam na escolha da trilha sonora. É importante informar que depois desta primeira organização os professores se mobilizaram dentro dos seus espaços e tempo de trabalho para a realização de ensaios objetivando a apresentação na mostra artística, nosso quarto encontro.

4. " Encontro, "Entrando em cena: a dança produzida por/para todos os corpos", finalizou todo este processo. Em outubro, uma Mostra de Dança foi organizada e todas as instituições apresentaram suas produções e reflexões acerca do processo vivenciado. Depois de cada grupo ocupar o palco com suas apresentações, houve um momento para a reflexão final deste trabalho. Um representante de cada instituição apresentou uma síntese das discussões realizadas nesses espaços, e as contribuições deste projeto no processo de formação continuada destes professores.

A metodologia do trabalho foi organizada da seguinte forma:

- Diagnóstico Situacional: realizado no primeiro encontro, consistiu-se em conhecer e descobrir as expectativas dos envolvidos, a partir das suas experiências vividas e leituras sobre dança e diversidade. Anteriormente ao encontro, foi disponibilizado aos envolvidos um texto para contextualização e apresentação do projeto e sua proposta para o ano de 2011.

- Vivências Práticas: realizadas em todos os encontros, caracterizou-se pela ação das atividades planejadas, objetivando a vivência, experimentação e criação em dança com foco no (re)conhecimento das possibilidades corporais, de forma individual e coletiva, possibilitando aos sujeitos envolvidos usufruírem da dança na perspectiva da educação estética, qual seja, dançar para ampliar as potencialidades humanas e (re)descobrir a beleza em todo movimento de dança, em todo corpo que dança, independentemente da sua condição corporal. As atividades práticas foram elaboradas a partir do diagnóstico situacional,das falas e envolvimento dos professores ao longo dos encontros.

- Grupos de diálogos - ao final de cada encontro o grupo reunia-se para discutir, refletir sobre as situações vivenciadas tentando visualizar as possíveis implicações pedagógicas dessas vivências.

Nesse caminho metodológico, os instrumentos utilizados foram o plano de ação, no qual constavam as atividades planejadas e o diário de campo, possibilitando-nos descrever as falas dos sujeitos durante e no momento final dos encontros e questionário com perguntas abertas ${ }^{1}$.

As reflexões que passamos a apresentar neste texto foram construídas a partir dos dados obtidos pela aplicação do questionário entregue aos participantes no final do terceiro 
encontro. Este constava de questões relativas aos momentos até então vivenciado se foram respondidos de forma espontânea/voluntária sem identificação pessoal, constando apenas a instituição na qual trabalhava. É importante ressaltar que embora professores (gênero masculino) participaram das oficinas, somente tivemos devolutiva do questionário respondido pelas professoras.

\section{1. ${ }^{\circ}$ Encontro: no movimento da dança de todos os corpos}

Falamos de um "ser corpo" que estabelece relações, que dialoga com os outros, que nos faz seres humanos com necessidades singulares e subjetivas; é pelo corpo que elaboramos um viver com sentido e significado de ser e estar no mundo e que nos compreendemos e nos constituímos sujeitos em movimento pela/na vida. Pelo corpo somos, estamos, interagimos com o mundo, revelamos nossa corporeidade.

Pensando a dança como uma vivência possível a todos os corpos, no primeiro encontro buscamos discutir e vivenciar a possibilidade de todo(s) o(s) corpo(s) dançar. Nisso questionamos: o que foi mais significativo para você nesse momento?

A professora B (APAE) ${ }^{2}$ afirmou:"o nosso corpo fala independente de qual o grau de movimento".Essa resposta remete à Gonçalves (1994), quando discute que o corpo-sujeito ao se-movimentar ${ }^{3}$, está em constante relação com o mundo, no qual todo movimento tem seu significado próprio a cada instante em que surge, estabelecendo um novo diálogo pessoal e próprio do homem com o mundo. Nisso também se aproxima a ideia da professora B (CAPP) quando afirma:"que este foi o momento em que pude experimentar o meu próprio corpo e perceber as tantas possibilidades que no dia a dia passa despercebido, consegui expor minhas possibilidades", ou ainda, quando afirmam que esse momento possibilitou "ver que cada pessoa tem um jeito de se expressar e interagir com o outro. Que cada um tem possibilidades diferentes para movimentar o corpo, de descobrir novas maneiras" (professora E - CAPP).

Estas respostas ajudam a entender que é pelo corpo que estabelecemos relações, que dialogamos com os outros, que nos constituímos como seres humanos com necessidades singulares e subjetivas. Também, conforme aprendemos com Merleau-Ponty (1999), é pelo corpo que elaboramos um viver com sentido e significado de ser e estar no mundo e, é por sermos corpos-sujeitos, que atuamos para/na (trans)formação da vida, da nossa existência. Assim, Pelo corpo somos, estamos e interagimos. 
Através das experiências e vivências de movimento, há uma busca de "atenuar-se na insistência de quem sabe que tem e sente um corpo. Apesar de cada sensação, percepção ser subjetiva ao ser, torna-se objetiva no momento de sentir" (ROCHA, 2008, p. 66).

Ter um corpo é de uma singularidade impressionante. O corpo pode lembrar ou ser muito parecido com o de alguém ou de outros, mas nunca é igual, até porque sua instância básica na dimensão espacial e temporal, da presença do aqui e agora, é moldada e atualizada a todo o momento. Ter consciência (capacidade de saber) e emoção (capacidade de sentir) também é singular, pelas mesmas razões já citadas. Especificamente na prática da conscientização do movimento tratamos de um corpo que sabe que sente, sabe que existe e sabe que sabe que existe e sente (TEIXEIRA, 2003, p. 73).

Em suas respostas alguns professores fizeram menção à ideia acima, como escreve a professora E (ADEVOSC): “o mais significativo foi a questão de nos descobrirmos como sujeitos, como um corpo que fala, que se expressa, e de que não há barreiras, limites para o corpo dançar". Ou ainda, que "esse primeiro momento serviu para desmitificar o conceito de dança, vendo-a a partir deste momento como possibilidade de todos os corpos" (professora X - APAE). Nessa perspectiva, podemos pensar que a dança se configura enquanto manifestação humana possível de modificações e inserção de novos conhecimentos baseandose nas experiências e possibilidades de cada "ser". O corpo que dança tem o privilégio de agir e provocar mudanças instituindo estados de movimento que inauguram um processo dialógico com o outro e com o mundo que o cerca.

Assim, o corpo em movimento é condição sine qua non para viver a corporeidade na totalidade humana de ser, estar e sentir-se corpo (ROCHA, 2008). Ou, ainda, como argumenta Trebels (2006), no corpo entendido como totalidade humana que abarca aspectos tantos biológicos quanto sociais e culturais, o movimento adquire uma importância fundamental, já que se vislumbra principalmente "a figura" do sujeito na ação corporal. Assim, "a capacidade humana de se movimentar ganha, então, uma dimensão existencial como forma singular e original de relação com o mundo: esta relação 'existir-para-o-mundo', a que todos nós pertencemos" (TREBELS, 2006, p. 34). Entendemos assim, que a dança, fenômeno que se mostra com o corpo-sujeito em movimento, agrega, nesse movimento de dança, sentidos e significados atribuídos ao(s) mundo(s) vivido(s).

Nessa perspectiva convergiram várias respostas dadas pelos professores: "Todos (corpos com deficiência ou sem deficiência) podem dançar e que dança não é uma atividade mecânica, precisa ser contextualizada, construída e que tenha significado" (professoraD - 
ADEVOSC); “independente deste corpo ser diferente (gordinho ou magro, com deficiência ou sem) existe um ser que tem potencial a ser explorado" (professora I - ADEVOSC);e, ainda conforme escreveu a professora A (CAPP) "todo corpo pode dançar. Não há barreiras para o corpo dançante".

A dança, no entendimento da professora S (APAE) torna-se "uma linguagem de expressão singular de cada um". Estas falas remetem pensar a dança, segundo aponta Rosa (2008, p. 63), como uma pré-disposição “a conhecer as habilidades e limitações do corpo, é procurar compreender a linguagem, os hábitos e a cultura que vão ao longo do tempo sendo registrados no corpo de cada um de nós".

As respostas das professoras fazem pensar que as experiências corporais possibilitam um saber-sentir pelo/no movimento, permitindo que corpo-sujeito atue com o "poder" de ir além de simplesmente fazê-lo, mas sim, senti-lo através da percepção do "meu ser/estar corpo" em movimento.

\section{2. ${ }^{\circ}$ Encontro: a dança e a possibilidade de (re)conhecimento do corpo outro - trilhando caminhos da sensibilização}

O segundo encontro do projeto Contradança em 2011, foi marcado pela experiência de sentir-se outro. Situações que proporcionaram experimentar o corpo com algumas limitações tais como: não enxergar, não ouvir e não caminhar provocaram intensa discussão a respeito do que entendemos como limitação, deficiência, possibilidade e superação. Apoiadas pelos princípios da educação estética nossa intervenção focou a sensibilização dos sujeitos para reconhecer a beleza e a possibilidades dos corpos.

Nosso entendimento do belo remete às ideias de Schiller, discutidas por Saraiva (2012), assim, “beleza não é algo que se configura numa forma (Gestalt) qualquer, e somente a sensibilidade humana pode experienciar essa forma e fazê-la viva em nosso entendimento; o que é sentido e entendido como belo será beleza" (p. 19).

Por isso entendemos ser importante a vivência de situações que remetem a sentir, pensar e agir de diferentes formas, ampliando as sensações corporais e permitindo construir novos olhares sobre nós mesmos, sobre nossas limitações e potencialidades. Apresentando a intrínseca relação entre corpo e sensibilidade Galeffi (2007) argumenta que "sem corpo não há sensibilidade, sem sensibilidade não há corpo. Toda sensibilidade, assim, é corpo vivente: 
modo de ser do que é em seu acontecimento anímico. A sensibilidade é o sentido do corpo. Tudo o que vive é sensível de múltiplas maneiras" (p. 98).

Um dos objetivos foi perceber como os professores se sentiram ao vivenciar as situações de limitações corporais, para isso questionamos: como foi passar por essa experiência?Algumas das respostas dadas pelos professores remetem à experiência singular de se colocar no lugar do outro ${ }^{4}$ : "foi muito gratificante, única, pois, temos dificuldade em nos colocar no lugar do outro (professora K - APAE); "Quando você vê é uma realidade, se colocar no lugar do outro é bem diferente" (professora A - APAE); "Foi um exercício de empatia e respeito a diversidade" (professora S - APAE); "Neste momento senti mais dificuldade ou desconfortável, pois, tentar pensar ou agir como o outro não é uma tarefa fácil, expressá-la é ainda mais" (professora V - APAE); "Foi muito importante para saber como o outro é importante na nossa formação do ser humano, do diferente (professora F - APAE); "Se colocar no lugar do outro é fundamental, principalmente para compreendermos que cada sujeito tem sua particularidade, com muitas possibilidades e habilidades (professora D ADEVOSC);

Essas respostas contribuem para pensar que poucas vezes, nas ações cotidianas, paramos para "estranhar" ou apreciar aquilo e aqueles que fazem parte da nossa rotina. O que percebemos é que a necessidade de produção exigida pelo mundo contemporâneo afeta também nossas relações pedagógicas e pessoais. Há urgência em tudo, estamos sempre com a sensação de que muitas coisas ainda estão por serem resolvidas. Nisso, a urgência para as coisas solapam nossa urgência para as pessoas, para o tempo de contemplação ao sujeito outro, tempo este, que nos possibilitaria aprender como outro e a admirar suas singularidades.

Outras respostas deram indicativos de que a dança foi compreendida para além do simples gesto motor. Ela implica o corpo como totalidade presente no instante da dança. Nesse sentido, a professora M (APAE) relata que neste momento "foi interessante perceber que pequenos gestos, olhares, representam expressões que se transformam em movimentos da dança"; Também para professora B (APAE) "a dança ocorre dentro de cada ser dançante independente da limitação do físico. A empatia ocorre devido à sensibilização que ocorre no momento da troca, sempre nos superamos e contribuímos com os outros".

Por fim, alguns relatos sugeriram que a experiência ofereceu oportunidades de redescobrir-se, implicando numa atitude diferente com relação a pensar e perceber o outro. Para a professora E (ADEVOSC), a experiência "foi bem marcante, pois, foi algo que nos fez pensar e agir como se estivéssemos no lugar do outro, fazendo-nos entender que nem sempre 
tudo o que é fácil para mim será para o outro. Cada corpo é um corpo que possui suas particularidades". Para professora B (ADEVOSC) "foi um momento rico, porque vivenciar estes limites nos fez pensar e viver mesmo que por alguns momentos como é o dia a dia do outro, ao mesmo tempo descobrindo as possibilidades nas limitações/restrições”.

De modo geral, as respostas deram indicativos de que a experiência provocou estranhamentos e sensações nem sempre confortáveis, mas profundamente enriquecedoras, como expressa a professora G (ADEVOSC), para a qual a vivência "provocou pensar em nossas ações". Isso permite concluir aquilo que Almeida (2001, p. 124), pontuou: “a cada nova experiência o corpo se remodela, possibilitando novas percepções de mundo [...] todo novo corpo é um novo sujeito no mundo". Ou, ainda, podemos concordar com Marcuse (apud Saraiva, 2012)quando afirma que a arte, neste caso a arte da dança, "não pode mudar o mundo, mas pode contribuir para a mudança da consciência e impulsos dos homens e mulheres, que poderiam mudar o mundo" (p. 30).

Estas reflexões nos levam ao encontro da dança como possibilidade para/de todos os corpos e ela se basta na sua materialização singular e sensível do corpo-sujeito que a sente, que a vive, criando a partir desta experiência novas perspectivas de (re)conhecimento da beleza do outro corpo, independente da sua condição corporal.

\section{3. ${ }^{\circ}$ Encontro: dançando com a diversidade}

A dança como possibilidades de todos os corpos se sustenta na singularidade e sensibilidade de cada corpo-sujeito que dança. No entanto, para quem dança buscando um padrão de corpo perfeito, o ato de dançar, ainda, se sustenta na padronização de movimento e de corpo, o que nega a possibilidade de ser corpo dançante na sua singularidade e na maneira de ser e estar no mundo. Porém para quem dança enquanto corpo-sujeito que é esta experiência se torna um ato sensível e significativo.

Buscamos no terceiro encontro experimentar as possibilidades coreográficas a partir dos elementos da criatividade, sensibilidade e expressividade.As vivências anteriores deram suporte para esta nova etapa do processo. Foi o momento de realizar encontros com ideias, sensações, movimentos e os outros corpos. Nossa intenção foi identificar como os participantes se sentiram no processo de pensar, sentir, fazer dança.

Para a professora S (APAE) "a sensação foi de que todos nós somos criativos, iguais e diferentes, isto é: a beleza da dança".Ainda, o sentimento para a professora D (ADEVOSC)foi 
de ter capacidade "criadora de uma coreografia que tinha significado para mim"; e que isso permitiu aos participantes perceber que "todos tem possibilidade de criar, de dançar" (Professora G - ADEVOSC);“Basta nos permitir” (professora B - CAPP).

Merleau-Ponty (1999), argumentou que toda a experiência é fonte de conhecimento e possibilita novo olhar para o fenômeno, sendo esse novo olhar através do meu corpo singular e do que eu construo com ele.

As experiências de nosso corpo construirão a nossa existência, darão significados a nossos projetos e ao conjunto de processos vividos. Experiências de um corpo pensamento, de um corpo arte, de um corpo que dança. De um corpo singular e universal, por consequência de suas experiências e de seus projetos (ROSA, 2008, p. 67).

Podemos compreender a dança como um fenômeno que, corporalmente manifestado, incumbe ao corpo a mediação entre o ser e o mundo numa totalidade vivida. Para SaraivaKunz (2003, p. 92) “[...] a dança é um fenômeno criado cuja presença vivida é uma experiência que faz emergir a reelaboração capaz de nos estimular muitas outras questões vitais para uma nova experiência". Nisso, a resposta da professora K (APAE) indica que o ato de dançar lhe faz sentir-se" criando, pensando e vivendo", possibilitando que esse corpo dançante se sinta, como indica a professora J (APAE) "realizado com capacidade de experimentar novos desafios, principalmente pensando em nossos alunos”.

Como fala Nóbrega (apud Gaio e Góis, 2006, p. 18),

A dança deriva da corporeidade do dançarino. A lógica da dança, sua configuração, encontra-se na interpretação/criação de movimentos. Para compreendê-la é preciso dançar, pois trata-se de um conhecimento vivencial, envolvendo o corpo, os movimentos e a percepção. A dança está diretamente vinculada ao corpo, sua linguagem é configurada pelo movimento, criando um vocabulário próprio de gestos significativos.

A dança é uma linguagem corporal de um texto cultural que permite ao corpo-sujeito expressar sentimentos e sensações através do "se-movimentar" intencional, expressivo e singular. Neste sentido, a professora D (CAPP), expressa: "me senti mais valorizada e importante: eu também posso dançar!”. Conforme aponta Saraiva-Kunz (2003, p. 126), “a dança configura um diálogo da pessoa com seu mundo, um diálogo onde se investe a expressão do mundo vivido". 
Também encontramos em Pellegrin, (2011, p. 30), a reflexão de que a dança,

É uma linguagem artística, é arte, tomada como um campo mais amplo, é uma das formas que o ser humano criou para se relacionar com o mundo: para entender o mundo, para questionar o mundo, para produzir respostas para muitas questões, para criar novos sentidos, novas formas de ser e fazer, para relacionar-se com os outros seres humanos.

Corroborando com esta ideia, Gaio e Góis (2006) argumentam que todo corpo pode dançar, quando acreditamos que a dança existe como uma expressão própria do ser humano e que esse ser humano de forma individual ou em grupo por meio de movimentos não-verbal expressa suas ideias com objetivos de denuncia ou libertação de algo. Segundo as autoras "a dança pode ser linguagem, para construção de uma nova cultura, de uma nova sociedade, de um novo mundo" (p. 19).

Acreditamos que a dança abre caminhos para a (re)elaboração e (re)leituras de mundo através das relações que ela nos permite compor com o espaço, o tempo e os outros corpos, difundindo a ideia de que o que nos enriquece, enquanto seres humanos, é a diversidade de situações e de sujeitos com os quais nos encontramos ao longo da vida, ou ainda, com a diversidade de corpos e de danças.

\section{Reflexões finais: a dança e a extensão universitária em cena}

Acreditamos que a dança possibilita outra forma de ser e estar no mundo, provocando uma ampliação na/da vivência do corpo em movimento em suas variadas formas e significações alicerçado, contudo, pela capacidade expressiva e intencional de movimento.

A relação de cada pessoa com a dança é algo diferenciada conforme sua vivência subjectiva e a realidade social. Ambas se reflectem na atribuição de significados que a pessoa faz, de forma que ela tem sempre uma compreensão biográfica da dança: cada pessoa tem formulado o significado que a dança tem para si (SARAIVA-KUNZ, 2003, p. 107).

Desta forma, as ações desenvolvidas pelo projeto de extensão Contradança foram traçando caminhos e encontros com a diversidade. As reflexões realizadas indicam a riqueza e a importância dos momentos dançados e discutidos, como relata a professora B da Adevosc, já que "possibilitou aos profissionais perceberem e se perceberem enquanto sujeito-corpo que 
dança", bem como, proporcionou desafios: "Foi desafiador, em especial a oportunidade de se colocar no lugar do outro, respeitando-o" (professora D - APAE).

Em todos os encontros nos preocupamos em provocar reflexões que transcendessem a ideia de pensar a dança como um simples movimento mecânico, mas como fenômeno repleto de vida já que quem dança é sempre um corpo-sujeito com toda a implicação que há nisto. A realização de (re)leituras do que (re)conhecemos como corpo/movimento/dança trouxeram novas possibilidades, como aponta uma professora da Adevosc: "Briguei com um certo 'preconceito'. Entendi a experiência sem igual. Levo várias ideias, novas possibilidades para agir e interagir com meus alunos".

Lançar outro olhar e olhar de forma diferente ao que acontece ao redor, no espaço que estamos inseridos, implica em abrir possibilidades para que a "beleza estranha" ou o incomum apareça aos olhos. Acreditamos que os encontros contribuíram para a construção de olhar(es)capaz(es) de perceber, ser tocado e sensibilizado pelo movimento próprio e do outro, da mesma forma pela dança que emerge dos diferentes corpos em movimento. Para uma professora da APAE esse projeto "mostrou novas possibilidades nas quais todos podem dançar"; e, principalmente fez perceber que para/na dança "não há limites e que é possível vencer barreiras. Algo comovente e ao mesmo tempo surpreendente, pois nota-se o quanto há superação da parte dos nossos educandos, pois apesar de todas as dificuldades, nos surpreendem a cada dança" (CAPP).

O resultado das intervenções reforçou nossa crença de que a dança possibilita ao ser humano uma compreensão de mundo de maneira diferenciada, ou seja, é um aprendizado que se alcança através do saber-sentir e pelo se-movimentar. Enquanto arte vivida a dança provoca ao corpo-sujeito formação de um "ser" mais crítico, sensível, criativo e atuante na sociedade que o envolve, já que podemos entender que vivenciar a dança é um meio de buscar em si mesmo, através dos movimentos corporais, a plenitude da vida (ROCHA, 2008).

Entendendo a dança como espaço de respeito e manifestação da diversidade, como caminho para o encontro com outros corpos-sujeitos, podemos trilhar tempos e movimentos pela ação intencional e nos descobrirmos enquanto sujeitos dançantes e atuantes no mundo. Podemos potencializar a dimensão denunciadora e crítica da dança, desenvolvendo a sensibilidade de quem a aprecia, de quem a produz e, principalmente, de quem a sente, indiferentemente da maneira de senti-la.

O que aprendemos com essas experiências é que todos necessitam do outro e que o outro tem papel fundamental na nossa constituição. As experiências que travamos com outros 
corpos inscrevem-se em nossos corpos, nos ensinam, nos alimentam. Constatamos que todos os participantes saíram alimentados de movimentos, de reflexões, de dúvidas e de estranhamentos. Acreditamos que este seja o desafio das ações extensionistas, o de promover articulações com a teoria e a prática, construindo diferentes saberes-fazeres. Para o projeto Contradança, a dança é o caminho para a promoção de encontros com o sensível, o vivido e o(s) sentido(s); a dança é o caminho para uma educação que tem como mote principal a constituição de sujeitos capazes de olhar e reconhecer no outro um pouco de si mesmo e, desta forma, compreender que a (in)diferença que diminui o outro, também acaba por diminuir o sujeito que olha, já que está incapaz de reconhecer e respeitar o outro em si.

Para finalizar recorremos às reflexões de Porpino (2006, p. 138) argumentando que "a dança pode ser compreendida como educação capaz de permitir e despertar um sentido de beleza, que não se prende a padrões ou a dicotomias, mas que rejunta fragmentos e abre novos horizontes para uma vida que não negue a sua própria realidade paradoxal"... acrescentamos: a dança pode ser compreendida como uma educação capaz de nos sensibilizar para a beleza de todos os corpos, nas suas singularidades e potencialidades reconhecendo a beleza das inúmeras danças que nascem dessas corporeidades, reveladas e reveladoras do mundo do qual fazem parte. A dança é capaz de nos ensinar que as possibilidades humanas nascem daquilo que mais tememos: dos limites humanos.

\section{Notas:}

1. O questionário foi aplicado somente nas instituições de ensino especializado, pois no decorrer do projeto as escolas da rede estadual de ensino adeririam à greve e nestes espaços, o projeto concentrou a terceira e quarta oficina no final de outubro, não sendo possível a aplicação do questionário.

2. Todas as falas serão trazidas desta forma: uma letra para identificar a professora e o nome da instituição à qual está vinculada.

3. Expressão cunhada por Elenor Kunz, ao se referir que o mais importante é perceber o "sujeito que se movimenta" e não, primordialmente, o movimento do sujeito. Na dança, essa ideia se traduz em valorizar o sujeito, sua singularidade, sua condição corporal (que é única) em movimento e não uma forma do movimento pré-determinada.

4. Sabemos da impossibilidade objetiva de se colocar ou viver a vida do outro. Porém o exercício de alteridade, ou seja, o exercício de nos aproximarmos da forma de ser do outro nos possibilita olhar de forma mais sensível para outro, reconhecendo sua forma/modo de ser e estar no mundo. 


\section{REFERÊNCIAS}

ALMEIDA, M. V. A sagração da primavera ou a sagração de um corpo do artifício. In: SOTER, S.; PEREIRA, R. (orgs) Lições de dança 3. Rio de Janeiro: UniverCidade, 2001.

GALEFFI, D. A.. Educação estética com atitude sensível transdisciplinar: o aprender a ser o que se é propriamente. Revista Em Aberto, Brasília, v. 21, n.77 jun/2007, p. 97-111.

Disponível em:

$<$ http://www.emaberto.inep.gov.br/index.php/emaberto/article/view/1168/1067> Acesso: 16.09.2007.

GAIO, R; GÓIS, A. A. F. Dança, Diversidade e Inclusão Social: sem limites para dançar! In: TOLOCKA, R. E; VERLENGIA, R. (orgs). Dança e diversidade humana. Campinas, SP: Papirus, 2006.

GONÇALVES, M. Sentir, pensar, agir: corporeidade e educação. São Paulo: Papirus, 1994.

MELO NETO, J. F. Extensão universitária e produção do conhecimento. Revista Conceitos. Jan/Jun, 2003.

MERLEAU-PONTY, M. Fenomenologia da percepção. 2. ed. São Paulo: Martins Fontes, 1999.

PELLEGRIN, A. Ensino de dança: finalidades, necessidades e identidades. In: CAMPÊLO, R; RODRIGUES, E. (orgs.). O ensino da dança no mundo contemporâneo: definições, possibilidades e experiências. Goiânia: Kelps, 2011.

PORPINO, K.O. Dança é educação: interfaces entre corporeidade e estética. Natal: EDUFRN, 2006.

ROCHA, D. Caminhos e possibilidades: uma proposta de dança na perspectiva educacional para pessoas com deficiência visual. Trabalho de Conclusão de Curso. Universidade Comunitária Regional de Chapecó, Curso de Educação Física, 2008.

ROSA, L. Uma experiência fenomenológica: o corpo que dança. In: XAVIER, J; MEYER, S; TORRES, V. (orgs). Coleção dança cênica: pesquisas em dança. vol.1 Joinville: Letradágua, 2008 . 
SARAIVA, M. C. Educação Estética: o prólogo da dança-arte-educação. Uma leitura em Schiller, Adorno e Marcuse. In: SARAIVA, M.C.; KLEINUBING, N.D. (orgs). Dança: diversidade, caminhos e encontros. Jundiaí: Paco Editorial, 2012.

SARAIVA-KUNZ, M. C. Dança e gênero na escola: formas de ser e viver mediadas pela educação estética.Tese de Doutorado em Motricidade Humana. Portugal, Universidade Técnica de Lisboa, 2003.

TEIXEIRA, L. Conscientização do movimento. In: Dança e Educação em Movimento, São Paulo: Cortez, 2003.

THIOLLENT, M. Metodologia da pesquisa-ação. 15. ed. São Paulo: Cortez, 2007.

TREBELS, A.H. A concepção dialógica do movimento humano: uma teoria do "semovimentar". In: KUNZ, E.; TREBELS, A.H. (orgs.) Educação Física críticoemancipatória: com uma perspectiva da pedagogia alemã do esporte. Ijuí: Unijuí, 2006. 